\title{
Response surface reconciliation method of bolted joints structure
}

\author{
Mohd Azmi Yunus ${ }^{1,2, *}$, Sharifah Nazri ${ }^{1,2}$, Mohamad Norhisham Abdul Rani ${ }^{1,2}$ \\ Azela Tormodi ${ }^{1,2}$ and Salmiah Kasolang ${ }^{1,2}$ \\ ${ }^{1}$ Faculty of Mechanical Engineering,Universiti Teknologi Mara,40450 Shah Alam, \\ Selangor, Malaysia \\ ${ }^{2}$ Structural Dynamics Analysis Validation, Universiti Teknologi Mara,40450 Shah Alam, \\ Selangor, Malaysia
}

\begin{abstract}
Structural joining methods such as bolted joints are commonly used for the assembly of structural components due to their simplicity and easy maintenance. Understandably, the dynamic characteristic of bolted joined structure is mainly influenced by the properties of their joints such as preload on the bolts and joints stiffness which alter the measured dynamics response of the structure. Therefore, the need to include the local effect of the bolted joints into the numerical model of the bolted joined structure is vitally important in order to represent the model accurately. In this paper, a few types of connector elements that can be used to represent the bolted joints such as CBAR, CBEAM and CELAS have been investigated numerically and experimentally. The initial numerical results of these element connectors are compared with the experimental results in term of natural frequencies and mode shapes. The comparative evaluation of numerical and the experimental data are performed in order to provide some insights of inaccuracies in the numerical model due to invalid assumption in the numerical modelling such as geometry, material properties, and boundary conditions. The discrepancies between both results (numerical and experimental data) are then corrected using the response surface reconciliation method (RSRM) through which the finite element model is altered in order to provide closer agreement with the measured data so that it can be used for subsequence analysis.
\end{abstract}

\section{Introduction}

In recent years, finite element (FE) models have become an important analysis tools for structural dynamics to produce numerically the dynamic behaviour of structures in mechanical systems. However, the finite element (FE) model of a structure is commonly constructed on the basis of design engineering and may not truly represent of an actual structure [1]. As a result, the numerical predictions from a finite element (FE) model

\footnotetext{
*Corresponding author: mayunus@salam.uitm.edu.my
} 
largely differ from the results of the real structure. These discrepancies originate from the uncertainties in simplifying assumptions of structural geometry, materials properties or boundary conditions [2]. In order to reduce these discrepancies, the uncertain parameters of a finite element (FE) model should be updated to leads the better predictions of the responses of an actual structure [3]. Many model updating techniques have been tested. Most techniques are based on the minimization of structural parameters to minimize an error function between the measured and numerical responses. There are two methods of model updating which are direct and iterative methods [4].

Direct methods of updating are directly update the finite element (FE) model properties commonly one step procedure while the iterative methods of updating uses the sensitivities of the parameters to find the changes and involving solution of an optimization problem [5]. Jaishi and Ren use the sensitivity updating methods that require complicated constructions of sensitivity matrices because the finite element (FE) models should be tuned and recomputed during optimization process [6]. Moreover, for a large finite element (FE) model, the evaluation of performance was repeated and local gradients are not only computational intensive but may also have result convergence difficulty when nonlinear complex structures are involved. Furthermore, each of the iteration in the iterative method needs to go back to run finite element (FE) with any parameter updated. Thus, in the field of model updating, computational efficiency is a major issue in the development of more applicable and practical approaches. Hence, an alternative technique for efficient computation of response of complex structures by overcoming the drawbacks of iterative method is Response Surface Methodology. Response Surface Method (RSM) is based on meta-modelling has emerged as an alternative solution to such problems to achieve balance. The primary advantages of the response surface method (RSM) in the updating method are its ease of implementation and low computational cost [7].

Response surface method has shown attractive ability in modifying finite element (FE) model parameters. Guo and Zhang present that the response surface method gave similarly accurate predictions while requiring much fewer number of finite element analyses compared with the sensitivity-based model updating [8]. Besides that, Zhang et al proposed a model updating technique based on generic algorithm and response surface methodology [9]. The present paper emphasizes the development of the connector element to represent as a bolted joined structure. As well, it is aimed to determine the better correlation between the experimental and finite element (FE) for bolted joined structure when updating the finite element (FE) model using response surface methodology (RSM).

\section{Experimental work}

The simplified model structure of bolted joined was developed. The completed bolted joined structure consists of two different types of components namely as plate and $\mathrm{u}$-shape. The u-shape is made from aluminium T60-6134 with the thickness of the top is $15 \mathrm{~mm}$ and the thickness of below $10 \mathrm{~mm}$. The plate is made of mild steel with the thickness of $1 \mathrm{~mm}$. There are in total seven bolted joints on the assembled structure. The experimental modal testing was performed to the bolted structure in free-free boundary conditions and the interest frequencies from $1 \sim 1000 \mathrm{~Hz}$ was used in the experiment. An impact hammer (PCB Model 086C02) and roving accelerometers (Dytran 3032A) were employed used in the measurement of the natural frequencies and mode shapes of the test structure. Then, the modal parameters from experimental work are obtained via the LMS data acquisition system. The finite element (FE) analysis results were employed to provide guidance on determining the frequency bandwidth of the testing, the locations of the excitation points, excitation directions and also response measurement points. As a result the model structure 
was set up as showed in Figure 1 in which four springs and nylon strings were used to simulate free-free boundary conditions of the structure.

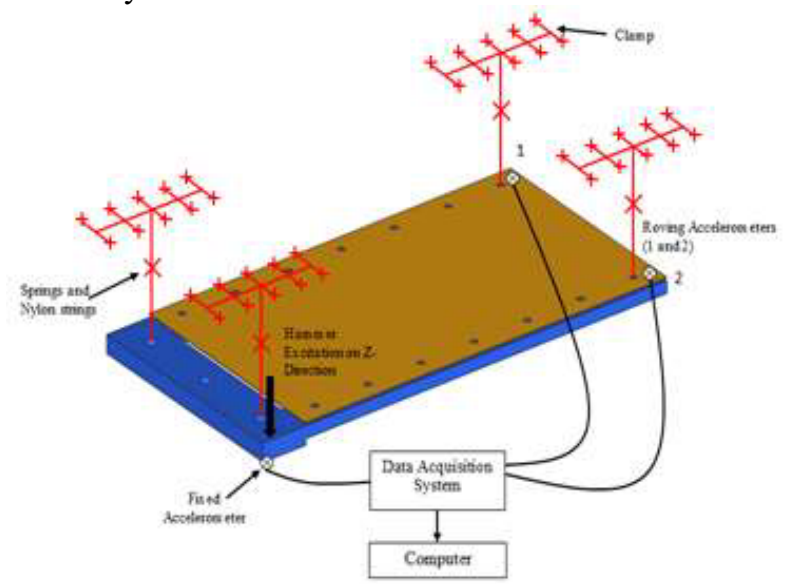

Fig. 1. Schematic diagram of bolted joined structure for experimental work.

\section{Finite element model and analysis}

The finite element models used in this study were developed using Altair HyperWork software as shown in Figure 2. Then, MSC PATRAN/NASTRAN Solution 103 and 200 were used for normal modes and sensitivity analysis respectively. In order to represent the bolted joints in the finite element model of the bolted joined structure, three types of connectors elements were used namely CBAR, CBEAM and CELAS. The material properties of mild steel and aluminium T60-6134 are used in the finite element model with nominal values as tabulated in Table 1.

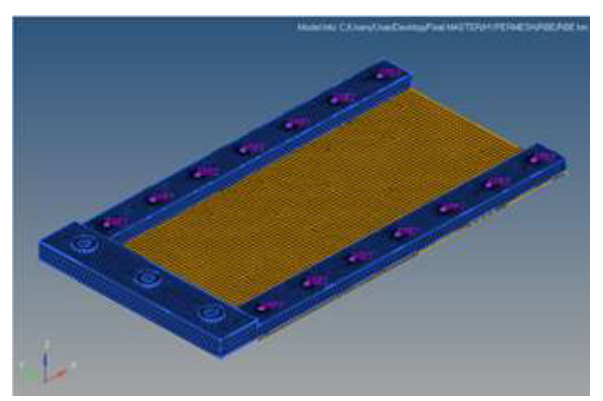

Fig. 2. Simplified CAE model of the bolted joined structure.

Table 1. Details of structure FE model.

\begin{tabular}{|c|c|c|c|}
\hline $\begin{array}{c}\text { Properties } \\
\text { (Mild Steel) }\end{array}$ & Value & $\begin{array}{c}\text { Properties } \\
\text { (Aluminum) }\end{array}$ & Value \\
\hline Young's Modulus & $210 \mathrm{GPa}$ & Young's Modulus & $69 \mathrm{GPa}$ \\
\hline Poisson's Ratio & 0.3 & Poisson's Ratio & 0.33 \\
\hline Density & $7900 \mathrm{~kg} / \mathrm{m}^{3}$ & Density & $2700 \mathrm{~kg} / \mathrm{m}^{3}$ \\
\hline
\end{tabular}


In this research, the MSC NASTRAN SOL103 was used for normal modes analysis. The governing equation of motion for the homogeneous system with absence damping is given as;

$$
\mathbf{M x}(\mathrm{t})+\mathbf{K x}(\mathrm{t})=0
$$

Where $\mathbf{M}, \mathbf{C}$ and $\mathbf{K}$ are represent as mass, damping and stiffness matrices of the system respectively. Then, $\mathbf{x}^{*}, \mathbf{x}^{*}$ and $\mathbf{x}$, known as vectors of accelerations, velocities and displacement respectively. The damping value in physical system can be disregarded for most engineering system due to its amount is so small [4]. The eigen-equation is applied in order to determine dynamic characteristics which are modes shapes and natural frequencies. It can be written as follows;

$$
\left(\mathbf{K}-\omega^{2} \mathbf{M}\right) \emptyset=0
$$

where eigenvalues $\omega^{2}$ are natural frequencies squared and $\emptyset$ are corresponding modes.

The initial natural frequencies and mode shapes of the bolted structures are computed using Altair HyperWork with free-free boundary condition to determine the frequencies and mode shapes of the structures.

\section{Response surface based on finite element model updating}

Response surface methodology is a combination of mathematical and statistical techniques useful for the modelling and analysis engineering problems in which a response of interest is influenced by several parameters and the objective is to optimize this response [10]. Furthermore, the choices of response surface function type are important. First order, the mathematical is able to describe the true relationship between input parameters and output responses. Usually, a low-order polynomial in some region of the independent variables is employed. If the response is well modelled by a linear function of the independent variables, the approximating function is the first order model as

$$
y=\beta_{o}+\sum_{i=1}^{\eta} \beta_{i} x_{i}
$$

Second order, this expression should contain the minimum number of items the increase of which will considerably increase the number of design points. For most engineering problems, a second-order polynomial function with interaction effects is adequate for representing physical systems:

$$
y=\beta_{o}+\sum_{i=1}^{\eta} \beta_{i} x_{i}+\sum_{i=1}^{\eta} \beta_{i i} x_{i}^{2}+\sum_{i=1}^{\eta} \sum_{j=1+1}^{\eta} \beta_{i j} x_{i}^{2} x_{j}+\varepsilon
$$

In, Eq. 1 and Eq. $2 \mathrm{y}$ is the response variable, $\beta_{0}$ is the constant term, $\beta_{\mathrm{i}}$ is the coefficient of the linear term, $\beta_{\mathrm{ii}}$ is the coefficient of quadratic single term, $\beta_{\mathrm{ij}}$ is the coefficient of the quadratic cross product term. The $\mathrm{x}_{\mathrm{i}}, \mathrm{x}_{\mathrm{j}}, \mathrm{x}_{\mathrm{k}}$ terms represent the main effect of parameter $\mathrm{i}$ and the interaction effect between $\mathrm{i}$ and $\mathrm{j}$, respectively. [11].

\section{Results and discussion}

The first ten frequencies of the bolted joined structure were calculated numerically using finite element method (FEM). The accuracy of the finite element models of the bolted 
joined structure with three types of element connectors was investigated. The result as shown in Table 2 consists of three types of comparisons with different types of connector element. The comparisons were made between test data and initial finite element data that show in summation of relative error for first ten modes. These relative errors might happen due to the deficiencies in the FE modelling. Non-linearity was one of the reason that the relative error which caused by the location and nature of joining especially in structure that made from metal [14]. On top of that, the assumptions input parameters (Young's modulus, Poisson's ratio, density and thickness) also influence the frequency of the structure.

As can be seen from the Table 1, the CBEAM connector element has shown the lowest error $(10.55 \%)$ connector compared to CBAR and CELAS element. The result also shows that the higher error is CELAS connector element which is $80.89 \%$ and followed by CBAR is $10.64 \%$ respectively. Therefore, CBEAM connector element was used to represent bolted joints of the assembled structure in the finite element model.

Table 2. Comparison of connector element.

\begin{tabular}{|c|c|c|c|c|c|c|c|}
\hline \multirow{2}{*}{ Mode } & \multirow{2}{*}{$\begin{array}{c}\text { Test Data } \\
(\mathbf{H z})\end{array}$} & \multicolumn{2}{|c|}{ CELAS } & \multicolumn{2}{c|}{ CBAR } & \multicolumn{2}{c|}{ CBEAM } \\
\cline { 3 - 8 } & & FE (Hz) & $\begin{array}{c}\text { Error } \\
\mathbf{( \% )}\end{array}$ & FE (Hz) & $\begin{array}{c}\text { Error } \\
\mathbf{( \% )}\end{array}$ & FE (Hz) & $\begin{array}{c}\text { Error } \\
(\mathbf{\%})\end{array}$ \\
\hline $\mathbf{1}$ & 123.15 & 163.25 & 32.57 & 124.35 & 0.98 & 124.24 & 0.89 \\
\hline $\mathbf{2}$ & 197.31 & 174.12 & 11.75 & 197.62 & 0.16 & 197.55 & 0.12 \\
\hline $\mathbf{3}$ & 205.62 & 209.95 & 2.11 & 208.71 & 1.50 & 208.66 & 1.48 \\
\hline $\mathbf{4}$ & 227.52 & 279.59 & 22.89 & 223.36 & 1.83 & 223.29 & 1.86 \\
\hline $\mathbf{5}$ & 303.44 & 288.59 & 4.89 & 295.02 & 2.77 & 294.96 & 2.79 \\
\hline $\mathbf{6}$ & 418.93 & 390.95 & 6.68 & 404.70 & 3.40 & 404.64 & 3.41 \\
\hline \multicolumn{2}{|l}{ Total Error (\%) } & & 80.89 & & 10.64 & & 10.55 \\
\hline
\end{tabular}

On the other hand, the response surface model updating was performed on the basis of the first six measured frequencies by minimising the objective function (Eq. 4). The updated values of the natural frequencies of the finite element model of bolted joints are shown in Table 2. From the table, it is clearly shown that, the total error of the updated natural frequencies is slightly reduced from 10.55 percent to 9.62 percent and MAC values are above 0.60 .

Table 3. Three comparisons of the results between the measured, the initial finite element model and updated model of the bolted structure (CBEAM).

\begin{tabular}{|c|c|c|c|c|c|c|c|}
\hline Mode & I & II & III & IV & V & VI & VII \\
\cline { 2 - 8 } & $\begin{array}{c}\text { Test Data } \\
(\mathbf{H z})\end{array}$ & $\begin{array}{c}\text { Initial FE } \\
\mathbf{( H z )}\end{array}$ & $\begin{array}{c}\text { Error } \\
\mathbf{( \% )} \\
{[\mathbf{I}-\mathbf{I I} / \mathbf{I}]}\end{array}$ & $\begin{array}{c}\text { Initial FE } \\
\text { MAC }\end{array}$ & $\begin{array}{c}\text { Updated } \\
\text { FE (Hz) }\end{array}$ & $\begin{array}{c}\text { Error } \\
\mathbf{( \% )} \\
{[\mathbf{I}-\mathbf{V} / \mathbf{I}]}\end{array}$ & $\begin{array}{c}\text { Updated } \\
\text { FE } \\
\text { MAC }\end{array}$ \\
\hline $\mathbf{1}$ & 123.15 & 124.24 & 0.89 & 0.98 & 122.14 & 0.82 & 0.97 \\
\hline $\mathbf{2}$ & 197.31 & 197.55 & 0.12 & 0.82 & 196.39 & 0.47 & 0.84 \\
\hline $\mathbf{3}$ & 205.62 & 208.66 & 1.48 & 0.93 & 205.35 & 0.13 & 0.88 \\
\hline $\mathbf{4}$ & 227.52 & 223.29 & 1.86 & 0.83 & 238.02 & 4.61 & 0.94 \\
\hline $\mathbf{5}$ & 303.44 & 294.96 & 2.79 & 0.83 & 310.27 & 2.25 & 0.97 \\
\hline $\mathbf{6}$ & 418.93 & 404.64 & 3.41 & 0.63 & 424.55 & 1.34 & 0.91 \\
\hline \multicolumn{2}{|r|}{ Total Error(\%) } & & 10.55 & & & 9.62 & \\
\hline
\end{tabular}




\section{Conclusions}

The bolted assembly structure was analysed by experimentally and numerically. The relative error was determined by comparing the natural frequencies and model shapes of the experimental result and numerical data. A replacement model of the bolted structure was updated using response surface method in reducing the value of relative error in term of the natural frequencies. It can be concluded that the cause of the error was contributed by the invalid assumption of the finite element model. Therefore, the continuous study in modelling bolted joint was recommended. It may be included the effect of deformation happen while joining process in further study in modelling bolted joints structure.

The authors would like to thank Kementerian Pendidikan Malaysia (KPM) and Research Management Centre (RMC) UiTM for the Fundamental Research Grant Scheme (FRGS) with the file number $600-\mathrm{RMI} / \mathrm{FRGS} 5 / 3$ (78/2014) for the sponsorship provided in completing this paper. The authors would like to express appreciation to En. Azwan bin Abd. Kadir, technician, Structural Dynamic and Validation (SDAV), UiTM for their technical assistance and laboratory facilities.

\section{References}

1. T. Marwala, Finite-element-model Updating Using the Response-surface Method, Finite element model Updat. Using Comput. Intell. Tech. Appl. to Struct. Dyn., pp. 103-125, (2010).

2. W.-X. Ren, H.-B. Chen, Finite element model updating in structural dynamics by using the response surface method, Eng. Struct., vol. 32, no. 8, pp. 2455-2465 (2010).

3. J.E. Mottershead and M.I. Friswell, Model Updating in structural dynamics: A survey, J Sound Vibration ,pp.167-347, (1993).

4. B. a. Zárate, J. M. Caicedo, Finite element model updating: Multiple alternatives Eng. Struct., vol. 30, no. 12, pp. 3724-3730 ( 2008).

5. S. Chakraborty, A. Sen, Adaptive response surface based efficient Finite Element Model Updating, Finite Elem. Anal. Des., vol. 80, pp. 33-40, (2014).

6. B. Jaishi, W.X. Ren, Structural finite element model updating using ambient vibration test results , J. Struct. Eng. , ASCE 131 (4) ,pp 617-628, ( 2005).

7. Q. Rui, H. Ouyang, H. Y. Wang, An efficient statistically equivalent reduced method on stochastic model updating, Appl. Math. Model., vol. 37, no. 8, pp. 6079-6096, (2013).

8. S. G. Shahidi, S. N. Pakzad, Response surface model updating for nonlinear structures, Proc. IMAC-XXXI Conf. Expo. Struct. Dyn. SEM, Orange County, CA, USA;, vol. 18015, (2013)

9. L. M. Zhang, Q. Fei, Q. T. Guo, Dynamic finite element model updating using metamodel and genetic algorithm, Proc., IMAC-XXIII Conf. Expo. Struct. Dyn. SEM, Orlando, FL, USA, (2005).

10. D.C. Montgomery, Design and Analysis of Experiments: Response surface methods and designs. New Jersey: John Wiley and Sons, Inc. (2005).

11. W. X. Ren, S. E. Fang, M. Y. Deng, Response surface based finite element model updating using structural static responses, $J$ Eng Mech-ASCE, vol. 137, no. Montgomery 2004, pp. 248-257, (2011). 